\title{
Potential Gain in Customer Value and Customer Satisfaction Index Method For Analysis of Customer Satisfaction Level (Case Study In Pt. Anteraja)
}

\section{Metode Potential Gain in Customer Value Dan Customer Satisfaction Index Guna Menganalisa Tingkat Kepuasan Pelanggan (Study Kasus Pada Pt. Anteraja)}

\author{
Sancha Arema Data ${ }^{1}$, Ribangun Bamban Jakaria ${ }^{2}$ \\ Program Studi Teknik Industri ${ }^{1}$, Fakultas Sains Dan Teknologi, Universitas Muhammadiyah Sidoarjo \\ Sanchadata@gmail.com ${ }^{1}$, ribangunbz@umsida.ac.id ${ }^{2}$
}

\begin{abstract}
UD PT. Tri Adi Bersama is a technology-based shipping service company known as Anteraja and sends packages by courier called Satria. This company is a supporter of Tokopedia's ecommers and will expand to other marketplaces. Currently, staging stores exist throughout Indonesia, except Papua. In the world of expedition or competing services from various companies, there are so many companies, but from all of that companies must think creatively in the services they provide to customers or consumers, companies must compete - competing for creativity in program problems that they will apply in their promotional system. Other online services have also been rampant in the general public and for competitors they also have promo programs and express facilities have tough challenges compared to other services which are only in the form of dropship services in staging areas. The Pick Up service is a service that is featured from the expedition of the Triputra group with a specified pick-up period, so the shiper or what can be called the shop owner can control and manage delivery schedules without being confused about delays in delivery The purpose of this research is to obtain complaint data to evaluate the level of customer satisfaction so that it can be used as a benchmark for companies in improving their service systems to customers using the CSI and PGCV methods.
\end{abstract}

Keywords - Customer Satisfaction, Service Quality, Facilities, Patrial Least Square Price

\begin{abstract}
Abstrak. UD PT. Tri Adi Bersama merupakan perusahaan jasa pengiriman yang berbasis teknologi sebagai salah satu andalan dengan sebutan Anteraja dan mengirim paket dengan kurir yang di sebut satria. Perusahann ini sebagia penyokong ecommers Tokopedia dan akan ekspansi ke marketplace - marketplace lain. Saat ini staging store sudah ada di seluruh indonesia kecuali Papua. Dalam dunia ekspedisi atau pun layanan jasa pesaing dari berbagai perusahaan sangat banyak, namun dari semua itu perusahaan harus berfikir kreatif dalam layanan yang dia berikan ke customer atau konsumen, perusahaan harus berlomba - lomba kreatifitas dalam masalah program yang akan mereka terapkan dalam sistem promosinya. Layanan online lainnya juga sudah merajalela dimayarakat umum dan untuk pesaingpesaing nya juga mempunyai progam promo dan fasilitas expres nya memiliki tantangan yang berat dibandingkan layanan yang lainnya yang hanya berupa pelayanan dropship di area-area staging. Pelayanan Pick Up merupakan layanan yang di unggulkan dari ekspedisi dari grup Triputra ini dengan periode penjemputan paket yang sudah di tentukkan, jadi shiper atau yang bisa disebut juga dengan owner toko bisa mengontor dan mangatur jadwal pengiriman tanpa bingung terjadinya keterlambatan pengiriman. Tujuan dari penelitian adalah untuk memperoleh data komplain untuk mengevalusi tingkat kepuasan pelanggan agar sebagai tolak ukur perusahaan dalam pembenahan sistem pelayanan ke pelanggan dengan metode CSI dan PGCV
\end{abstract}

Kata Kunci - Kepuasan Konsumenn, Kualitas Pelayanan, Fasilitas, Harga Patrial Least Square

\section{Pendahuluan}

Pada Abad ini adalah abad dimana teknologi jasa dan platform, saling berhubungan dan saling terkoneksi dalam bekerjasama[1]. Dimana Setiap orang mampu menciptakan model- model bisnis baru yang kreatif dan memiliki pengaruh yang sangat luas di bidang pelayanan dan ekonomi. Semua orang dapat berkereasi dalam peningkatan prospek bisnis. Dalam perkembangan saat ini yang sangat cepat dalam dunia digital ekonomi dan jasa semua orang diberbagai negara dapat mengetahui barang yang lebih murah [2]dari lintas negara, dan mereka berlomba-lomba untuk memenangkan hati konsumen dalam upaya pemberian barang[3]. Dengan adanya percepatan pada dunia teknologi, 
semakin tingginya mobilisasi masyarakat, munculah beberapa pengusaha muda yang meluncurkan model bisnis baru yang bergerak pada teknologi pelayanan jasa dan ecommers yang saling berhubungan. Itu merupakan startup jasa yang baru berdiri pada tahun 2019 di Indonesia yang melayani pengiriman barang berbasis teknologi. Hadirnya kreativitas pelayanan memberikan warna baru pada dunia ekpedisi dan berdampak positif ke perekonmian digital indonesia yang terintergrasi pada pelayanan Pick Up untuk pendukung pertumbuhan pengguna ecommers di indonesia juga mempersiapkan diri untuk bekerja sama dengan berbagai ecommerce, marketplace dan pengguna lainnya. Para pekerja di eduksi sebagai pendukung peningkatan ecommers di indonesia yang bekerja sesuai standar operasional yang sudah di tetapkan. Dari uraian penjelasan di atas peneliti tertarik mendalami untuk melakukan analisis kualitas pada layanan pada ekspedisi dari Triputra grup ini yaitu ekspedisi Anteraja. Karena banyaknya respon yang terjadi di dalamnya dari segi kepuasan pelayanan yang diberikan yang bedampak negatif dan positif. Dari respon positif konsumen dapat menggunakan layanan yang lebih murah dan efesien[4], karena kita menggunakan pelayana Pick Up langsung ke tempat alamat tertera tanpa ada batasan jumlah barang yang di Pick Up dan waktu ekskalasi pengambilan yang sudah ditetapkan, sedangkan untuk ekepedisi yang lain masih mengirim sendiri di staging area meskipun bisa di pick up namun ada batasan minimal baranng yang bisa di Pick Up. Terlebih dengan jumlah penggunan aplikasi Android maupun IOS yang saat ini tersebar di indonesia sangat membantu peningkatan penggunakan layanan, sayang nya untuk aplikasi ekspedisi Anteraja masih dalam proses pembuatan sampai saat ini. Disisi negatif banyak complain tentang pelayanan yang berkaitan dengan pihak ekspedisi seperti dalam hal penampilan dan sarana fisik yang belum dapat dijangkau dengan mudah. Hal tersebut membuat ketanggapan dalam pelayanan menjadi terhambat.[5]

\section{METODE}

Dalam tahap ini pengolahan data dilakukan dengan beberapa proses menggunakan perhitungan sebagai berikut[6][7]

1. Menggunakan metode CSI ( Customer Satisfaction index)[8]

Evaluasi model pengukuran dengan menggunakan metode CSI ada beberapa tahap untuk pencarian data seperti di jabarkan di bawah ini adalah[7]

a. Mean Importand Score (MIS)[9]

b. Weight Factor (WF) [10]

c. Wight Score (WS) [11]

2. Menggunakan metode PGCV[12]

Evaluasi model pengukuran dengan menggunakan metode PGCV ada beberapa tahap untuk pencarian data seperti di jabarkan di bawah ini adalah.[13]

a. Achive Customer Value ( ACV) [14]

b. Ultimately Desire Customer Value (UDCV)[15][16]

3. Uji Hipotesis[17][18][19][20]

Setelah melalukan evaluasi outer model dan inner model selanjutnya adalah melakukan pengujian hipotesis. Uji hipotesis digunakan untuk menjelaskan arah hubungan antara variabel independen dan variabel dependenya.

Pemaparan metoda penelitian harus detail, utamanya mengenai metoda apa yang digunakan dan data-data apa yang digunakan dari suatu penelitian.

\section{Hasil Dan PeMbahasan}

\section{A. Customer Satisfaction Index ( CSI)}

Dalam perhitungan CSI bias didapatkan dari nilai rataan tingkat kepentingan dan nilai rataan kinerja dari masing-masing acuan bobot penilaian. Contoh perhitungannya untuk atribut 1 dan hasil pada tabel 1 sebagai berikut :

1. Rata-rata Kepentingan : $\bar{Y}=\frac{\sum Y i}{n}=\frac{5+4+4+5+\cdots \ldots+4}{40}=4,53$

2. $\mathrm{WF} \%=\frac{\bar{Y}}{\left(\sum_{i=1}^{p} \bar{Y}\right): \text { Responden }}=\frac{4,53}{0,95}=4,76$

3. Rata-rata kepuasan : $\bar{X}=\frac{\sum X i}{n}=\frac{4+5+4+3+\cdots \ldots+4}{40}=4,10$

4. $\mathrm{WS}=\mathrm{WF} \% \times \bar{X}=4,76 \% \times 4,10=19,53$ 


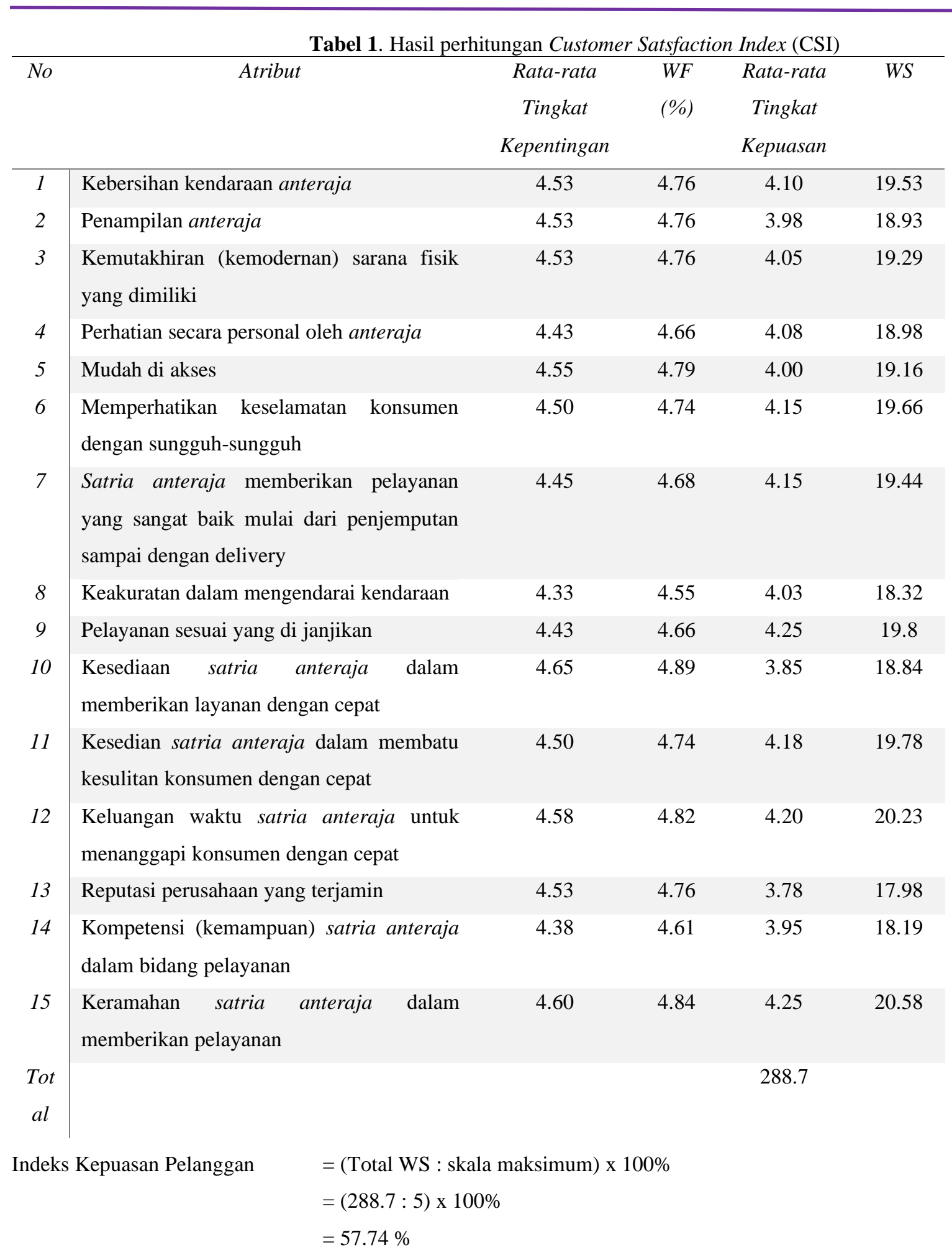

Berdasarkan dari hasil tabel perhitungan yang telah dilakukan menggunakan CSI dapat diketahui bahwa indeks kepuasan pelanggan terhadap pelayanan Satria Anteraja sebesar $57.74 \%$ pada rentang skala 51 sampai dengan 65. Dapat dikatakan bahwa tingkat kepuasan pelanggan disana secara umum berada pada kategori cukup puas yang berarti masih ada dua lagi tingkatan, maka dari itu tingkat pelayanan dari Satria Anteraja perlu ditingkatkan lagi.

\section{B. Potential Gain in Customer Value (PGVC)}

Dari data hasil Importance- performance Analysis, di haruskan melakukan penentuan urutan prioritas perbaikan pelayanan dengan mengunakan indeks Potential Gain in Customer Value (PGCV) dalam upaya mengetahui angka prioritas perbaikan pelayanan yang harus dilakukan dan di jalankan. Untuk mendapatkan nilai PGCV, yang harus di lakukan yaitu mencari dan menentukan nilai ACV (Achieved Customer Value) dan UDCV (Ultimately Desired 
Procedia of Engineering and Life Science Vol. 1. No. 2 Juni 2021

Seminar Nasional \& Call Paper Fakultas Sains dan Teknologi (SENASAINS 2nd)

Universitas Muhammadiyah Sidoarjo

Customer Value). Data mengenai indeks PGCV akan disajikan pada Tabel 2. Langkah-langkah menghitung $P G C V$ adalah :

a. Achiive Customer Value (ACV)

$A C V=X \times Y$

Dimana : $X=$ Skor rata-rata kinerja

$Y=$ Skor rata-rata kepentingan

b. Ultimately Desire Customer Value

$U D C V=Y \times X \max$

Dimana $: Y=$ Skor rata-rata tingkat kepentingan

$X \max =$ Nilai maksimal skala Likert

c. Indeks $P G C V$

Indeks $P G C V=U D C V-A C V$

Tabel 2 Index PGCV

\begin{tabular}{c|cccccc}
\hline ATRIB & NILAI RATA- & NILAI RATA-RATA & NILAI & NILAI & NILAI & PRIORITAS \\
UT & RATA TINGKAT & $\begin{array}{c}\text { TINGKAT } \\
\text { KEPUASAN }\end{array}$ & AVC & UDCV & PGCV & \\
& KEPENTINGAN & & & & \\
$\mathbf{X 1}$ & 4.10 & 4.53 & 19.53 & 22.63 & 3.10 & 9 \\
$\mathbf{X 2}$ & 3.98 & 4.53 & 18.93 & 22.63 & 3.69 & 3 \\
$\mathbf{X 3}$ & 4.05 & 4.53 & 19.29 & 22.63 & 3.33 & 6 \\
$\mathbf{X 4}$ & 4.08 & 4.43 & 18.98 & 22.13 & 3.14 & 8 \\
$\mathbf{X 5}$ & 4.00 & 4.55 & 19.16 & 22.75 & 3.59 & 5 \\
$\mathbf{X 6}$ & 4.15 & 4.50 & 19.66 & 22.5 & 2.84 & 10 \\
$\mathbf{X 7}$ & 4.15 & 4.45 & 19.44 & 22.25 & 2.81 & 11 \\
$\mathbf{X 8}$ & 4.03 & 4.33 & 18.32 & 21.63 & 3.30 & 7 \\
$\mathbf{X 9}$ & 4.25 & 4.43 & 19.80 & 22.13 & 2.33 & 15 \\
$\mathbf{X 1 0}$ & 3.85 & 4.65 & 18.84 & 23.25 & 4.41 & 2 \\
$\mathbf{X 1 1}$ & 4.18 & 4.50 & 19.78 & 22.5 & 2.72 & 12 \\
$\mathbf{X 1 2}$ & 4.20 & 4.58 & 20.23 & 22.88 & 2.65 & 13 \\
$\mathbf{X 1 3}$ & 3.78 & 4.53 & 17.98 & 22.63 & 4.64 & 1 \\
$\mathbf{X 1 4}$ & 3.95 & 4.38 & 18.19 & 21.88 & 3.68 & 4 \\
$\mathbf{X 1 5}$ & 4.25 & 4.60 & 20.58 & 23 & 2.42 & 14 \\
& & & & & &
\end{tabular}

Berdasarkan tabel tersebut dilakukan pengurutan sesuai yang memiliki nilai PGCV terbesar hingga terkecil untuk mengetahui atribut mana yang memiliki prioritas untuk dilakukan perbaikan.

\section{Langkah-langkah Perbaikan}

Berdasarkan hasil analisa Importance and Performance Analysis (IPA) yang memerlukan perbaikan adalah pada kuadran 1. Pada kuadran tersebut merupakan prioritas utama dalam hal perbaikan. Berikut adalah perbaikan pada kuadran 1. 


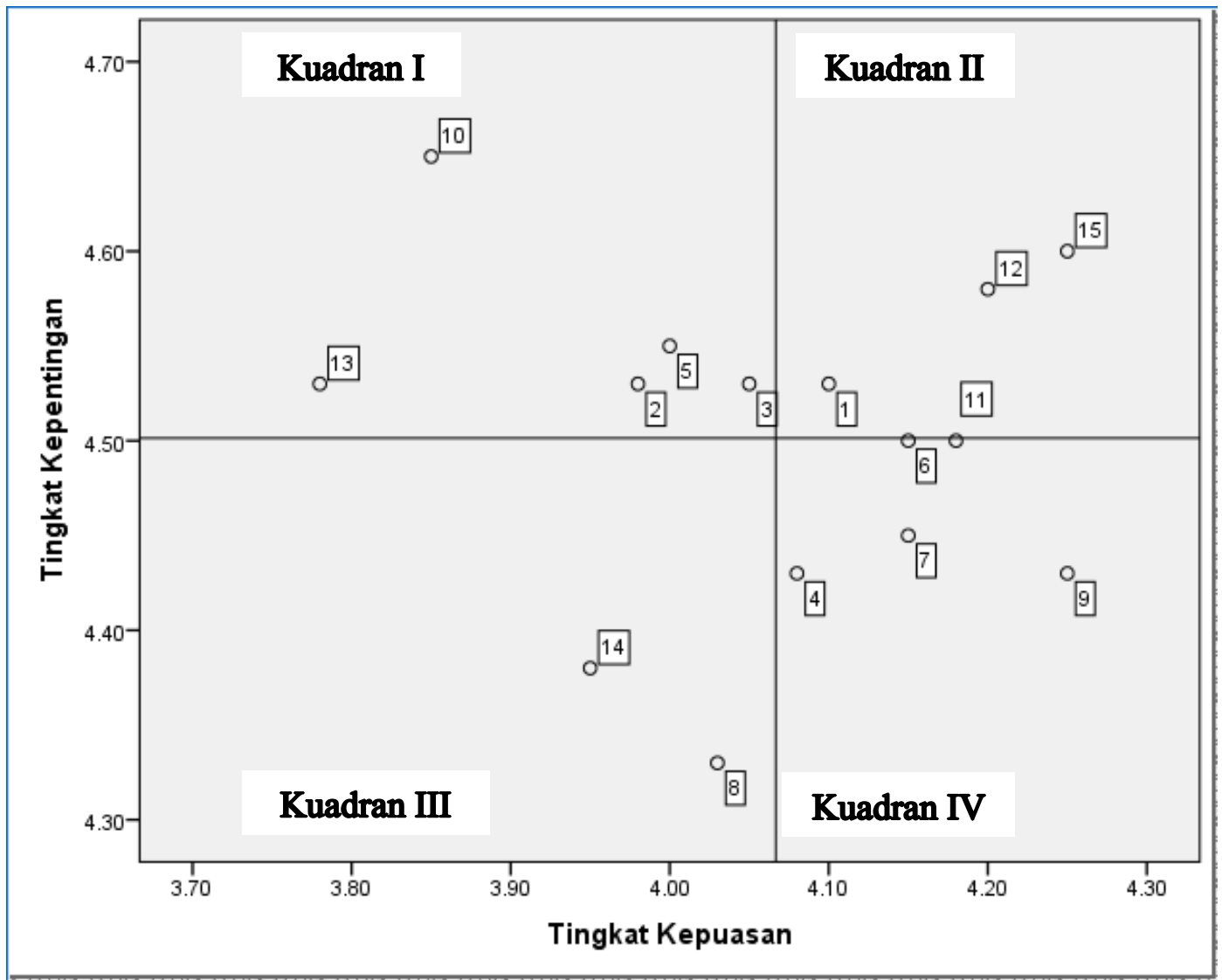

Gambar 1. Diagram Kartesius

1. Pada atribut dua yaitu "penampilan anteraja" perlu adanya perbaikan dengan memberikan arahan pada karyawan agar terlihat lebih baik. Penampilan merupakan salah satu hal yang penting ketika bertemu langsung dengan customer. Para karyawan dituntut untuk berpenampilan menarik agar customer merasa nyaman.

2. Pada atribut tiga yaitu "Kemutakhiran (kemodernan) sarana fisik yang dimiliki" perlu diperbaiki dalam hal sarana fisik. Pembaruan pada sarana fisik untuk menunjang kinerja karyawan. Sarana fisik juga membuat customer merasa nyaman saat menggunakan pelayanan satria anteraja.

3. Pada atribut lima yaitu "mudah diakses" perlu perbaikan dalam hal akses mengakses pelayanan. Sering kali customer merasa sulit untuk mengakses pelayanan karena kurangnya petunjuk dalam menggunakan pelayanan.

4. Pada atribut 10 yaitu "Kesediaan satria anteraja dalam memberikan layanan dengan cepat" memerlukan perbaikan terhadap kurangnya ketanggapan karyawan. Ketanggapan sangat penting untuk efisiensi pekerjaan dan juga waktu. Customer juga dirugikan dalam hal waktu jika karyawan kurang tanggap.

5. Pada atribut 13 yaitu "Reputasi perusahaan yang terjamin" lebih diperbaiki lagi agar pelanggan merasa terjamin ketika menggunakan layanan satria anteraja. Jaminan yang kuat akan menumbuhkan rasa aman bagi customer.

\section{KESIMPULAN}

Berdasarkan hasil pengujian dan pembahasan yang telah dilakukan dalam bab 4 maka dapat disimpulkan sebagao berikut. (1) Respon customer terhadap pelayanan cukup baik karena pada keputusan Hold dan Action lebih banyak Hold yang artinya banyak pelayanan yang memenuhi keinginan customer. Hold yang didapatkan sebanyak 11 dan sisanya action 4. (2) Berdasarkan hasil perhitungan Customer Satisfaction Index (CSI) didapatkan indeks sebesar 57,74\%. Sehingga tingkat kepuasan customer adalah Cukup Puas. Namun masih ada 2 tingkatan yang perlu dicapai untuk menjadi lebih baik. (3) Solusi dari manajemen pada pelayanan anteraja adalah memperbaiki dari kuadran 1 dari diagram kartesius, yaitu: (a) Para karyawan dituntut untuk berpenampilan menarik agar customer merasa nyaman. (b) Sarana fisik juga membuat customer merasa nyaman saat menggunakan pelayanan satria anteraja. (c) Perbaikan dalam hal akses mengakses pelayanan. (d) Ketanggapan sangat penting untuk efisiensi pekerjaan dan juga waktu. Customer juga dirugikan dalam hal waktu jika karyawan kurang tanggap. 


\section{UCAPAN TERIMAKASIH}

Ucapan terima kasih terutama ditujukan kepada pemberi dosen pembibing dan rekan rekan yang membantu saya menyelesaikan tugas akhir pelaksanaan penelitian.

\section{REFRENSI}

[1] Y. Siyamto, "Kualitas Pelayanan Bank Dengan Menggunakan Metode IPA Dan CSI Terhadap Kepuasan Nasabah," J. Ilm. Ekon. Islam, vol. 03, no. 01, pp. 63-76, 2017.

[2] R. B. Jakaria, H. Widodo, N. Haizal, and M. B. Ibrahim, "Analytic Hierarchy Process Method for Minimize Negative Sustainability and Environmental Impacts," IOP Conf. Ser. Earth Environ. Sci., vol. 519, no. 1, 2020, doi: 10.1088/1755-1315/519/1/012054.

[3] R. B. Jakaria, A. Wisaksono, and Fajrilah, "Perancangan Sistem Informasi Suppy Chain Produk Usaha Mikro Kecil Menengah,” J. Manaj. Bisnis, vol. 32, no. 1, pp. 77-81, 2019.

[4] R. B. Jakaria, Iswanto, N. binti M. Y. Ariffin, and M. bin Ibrahim, "Analytic Hierarchy Process (AHP) Method for Measuring the Dominance of Product Design Against Industry Criteria 4.0," Proc. 2nd Int. Conf. Bus. Manag. Technol. (ICONBMT 2020), vol. 175, pp. 195-201, 2021, doi: 10.2991/aebmr.k.210510.033.

[5] A. Usmara, Strategi Baru Manajemen Pemasaran. Yogyakarta: Amoro Book, 2003.

[6] E. Budi P, Rahasia Sukses Membangun dan Mengelola Bengkel / Toko Spare Part Motor. Semarang: Dahara Prize, 2009.

[7] Sugiyono, Metode Penelitian Kuantitatif, Kualitatif dan R \& D. bandung: alfabeta, 2014.

[8] M. Singarimbun, Metodologi Penelitian Survey. Jakarta: LP3ES, 1989.

[9] Supranto, Pengukuran tingkat kepuasan pelanggan. Jakarta: Bineka Cipta, 2001.

[10] Suriasumantri, Filsafat Ilmu : Sebuah Pengantar Populer. Jakarta: Pustaka Sinar Harapan, 2001.

[11] Walpole, Ilmu Peluang Dan Statistika untuk Insinyur dan Ilmuawan, 4th ed. Bandung: ITB.

[12] Anipiyani, “Analisis Kualitas Pelayanan yang Mempengaruhi Minat Beli Konsumen,” J. Progr. Pascasarj., 2005.

[13] O. Ardhana, “Analisis Pengaruh Kualitas Pelayanan, Harga dan Lokasi Terhadap Kepuasan Pelanggan,” J. Univ. Diponegoro Semarang, 2010.

[14] R. A. Devani, V., \& Rizko, "Metode Customer Satisfaction Index ( CSI ) dan Potential Gain in Customer Value ( PGCV )," J. Rekayasa Dan Manaj. Sist. Inf., vol. 2, pp. 24-29, 2016.

[15] A. Dewi, S. K., Restuputri, D. P., \& Sulaksmi, "Analisis Kepuasan Pelanggan Dengan Pendekatan Metode Customer Satisfaction Index Dan Importance Performance Analysis," pp. 978-979, 2015.

[16] W. C. Hom, Make Customer Service Analyces A Little Easier With The PGCV Index. Quality Progres Journal, 1997.

[17] D. Diniaty, "Analisis Kualitas Pelayanan terhadap Kepuasan Masyarakat atau Pasien di RSUD Tengku Rafi'an Kab Importance Performance Analysis dan Potential Gain in Customer Value," J. Has. Penelit. Dan Karya Ilm. Dalam Bid. Tek. Ind., vol. 2, p. 25, 2016.

[18] D. Fahamsyah, "Pengukuran Indeks Kepuasan Masyarakat (Ikm) Pelayanan Kesehatan Di Puskesmas Kabupaten Hulu Sungai Utara," J. Adm. Kesehat. Indones., vol. 6, p. 189, 2018.

[19] Y. Siyamto, "Kualitas Pelayanan Bank Dengan Menggunakan Metode Importance Performance Analysis (Ipa) Dan Customer Satisfaction Index (Csi) Terhadap Kepuasan Nasabah,” J. Ilm. Ekon. Islam, vol. 3, p. 63, 2017.

[20] Widodo, "Metode Customer Satisfaction Index (CSI) Untuk Mengetahui Pola Kepuasan Pelanggan Pada Ecommerce Model Business to Customer," J. Inform. Upgris, vol. 4, pp. 38-45, 2018. 